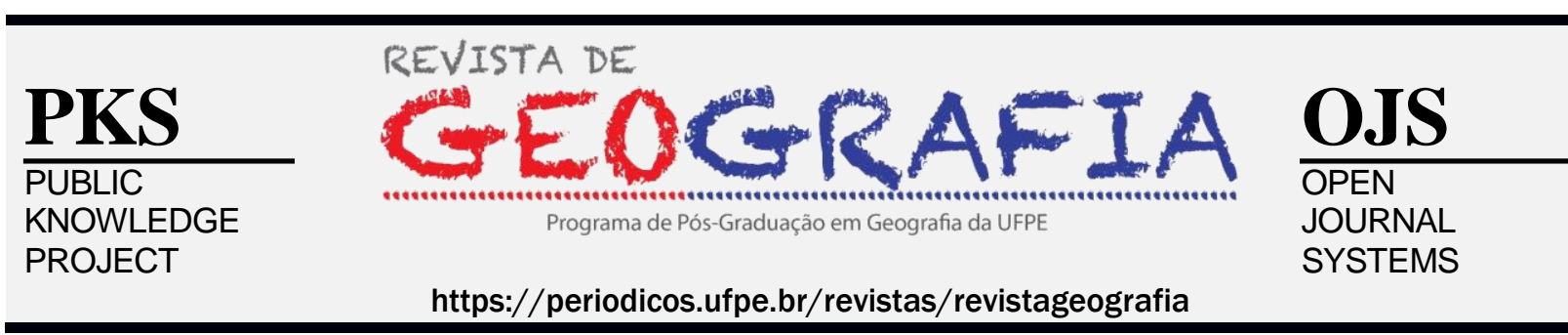

\title{
INFLUÊNCIA DO USO DO SOLO EM PARÂMETROS CLIMÁTICOS DE SÃO BENTINHO-PB
}

\author{
Maria de Fátima Araújo Alves ${ }^{1}$, Silvana Nóbrega de Andrade², Guilherme Veloso da \\ Silva $^{3}$, Marcelo Augusto Rocha Limão ${ }^{4}$, Nauam Ribeiro Marques Cirilo ${ }^{5}$
}

\author{
${ }^{1}$ Mestranda em Engenharia Ambiental - UFRPE, Recife-PE.l. E-mail: mariaufcg2013@gmail.com \\ ${ }^{2}$ Mestranda em Sistemas Agroindustriais - UFCG, Pombal-PB. E-mail: silvananobreri@hotmail.com \\ ${ }^{3}$ Mestrando em Ciências Florestais- PPGCF-UFCG-Patos-PB. E-mail: guilherme_ccta@hotmail.com \\ ${ }^{4}$ Graduando em agronomia - UFCG, Pombal-PB. E-mail: marceloliimao@gmail.com \\ ${ }^{5}$ Graduando em Engenharia Florestal -UFCG, Patos-PB. E-mail: nauan.cirilo@hotmail.com
}

Artigo recebido em 03/05/19 e aceito em 06/07/19

\begin{abstract}
RESUMO
As necessidades humanas atreladas ao crescimento populacional implicam sobre o consumo dos recursos naturais, tornando-os insuficientes. O presente trabalho tem como objetivo fazer um estudo comparativo entre 5 pontos de um raio de $30 \mathrm{~m}^{2}$ na zona rural, localizados no município de São Bentinho-PB, no que diz respeito à diferença entre os dados de temperatura e umidade relativa do ar, levando em consideração os usos do solo. A metodologia utilizada consistiu em fazer uma comparação entre os valores de temperatura e umidade do ar de cinco pontos amostrais de usos do solo diferentes. Para tal objetivo, coletou-se dados de temperatura e umidade relativa do ar por meio de aparelho digital termo-higrômetro, durante os meses de dezembro de 2018 a fevereiro de 2019. Para determinar o uso do solo, utilizou-se imagens de satélites Landsat 5 e classificou-se as imagens por meio da classificação supervisionada no Qgis e elaborou-se os mapas de cada uma das amostras. Os dados determinados foram comparados na intenção de explicar as diferenças observadas no uso do solo. Observou-se uma temperatura do ar mais elevada e uma menor UR para o ponto 2 . O ponto com o uso do solo mais diferente do natural foi o ponto 2 com $78 \%$ do solo exposto. Dos resultados conclui-se que o uso do solo tem influência positiva no aumento nos parâmetros climáticos observados.
\end{abstract}

Palavras-chave: Antropização; Uso do solo; Semiárido brasileiro.

\section{ANALYSIS OF THE INFLUENCE OF LAND USE ON CLIMATE PARAMETERS OF SÃO BENTINHO-PB}

\begin{abstract}
The human needs associated with the growth of the population implies over-consumption of natural resources, making them scarce. The present work has as objective to make a comparative study of 5-points with a range of $30 \mathrm{~m} 2$ in the rural area, located in the city of Sao Bentinho - PB, with respect to the difference between the temperature and the relative humidity of the air, and, in consideration of the use of the land. The methodology used consisted in the comparison between the measured values of the temperature and the humidity of the air, the ve-point sampling for land use to be different. For this purpose, he collected data on temperature and relative humidity of the air by means of a appliance, a digital thermo-hygrometer, and during the summer months from December 2018 to February 2019 at the latest. In order to determine the use of the land, we used satellite imagery from Landsat 5 and qualified with the images by means of supervised classification in Qgis, and set up the maps for each of the samples. All such data were compared with the intent of explaining the observed differences in the use of the land. There has been a temperature of the air, the highest and the lowest $\mathrm{RH}$ for the
\end{abstract}


step 2. The point is, with the use of the soil, other than the natural, to-the-point 2 , with $78 \%$ of the land is exposed. From the results, it was concluded that the use of the land has a positive influence on the increase in the climatic parameters are observed.

Keywords: Anthropisation; Use of the soil; Brazilian semi-arid.

\section{INTRODUÇÃO}

As necessidades humanas atreladas ao crescimento populacional implicam sobre o consumo dos recursos naturais, tornando estes insuficientes. Quanto maior o aumento populacional, mais necessidade de expansão de áreas antropizadas existem, tanto nas cidades (expansões urbanas) quanto nas zonas rurais (supressão da vegetação nativa para a produção agrícola ou pecuária) (CORAZZA; NECKEL; CAMBRUSSI, 2018).

A urbanização gera problemas em esferas de ordem ambiental e social, sendo estas esferas variantes de acordo com o grau de desenvolvimento das nações, bem como o empenho destas com o meio ambiente (LIMA, 2012). A urbanização causou grandes impactos ambientais nas cidades em que se processou com maior intensidade (LEAL et al., 2008). São Bentinho é uma das pequenas cidades do interior da Paraíba, que aos poucos vem se desenvolvendo e utilizando os recursos naturais para esse crescimento e gerando poluição.

Fogliatti et al (2004) acrescenta que a concentração de fontes de poluição na cidade deve-se as migrações provenientes de campos e das cidades menores em busca de melhores oportunidades econômicas, sobrecarregando a infraestrutura da mesma e degradando o ambiente e diminuindo a qualidade de vida.

Porém, a zona rural possui os menores índices de poluição e por isso é considerada como concentração padrão em relação aos centros urbanos (PIRES, 2005). Mas, ultimamente, com a necessidade de expansão das áreas para agricultura e pastos, esse cenário vem sendo modificado em larga escala. O desmatamento tem sido a causa principal, resultando em alteração das paisagens naturais, mudanças na configuração de uso do solo e consequentemente nos parâmetros climáticos (CORAZZA; NECKEL; CAMBRUSSI, 2018).

Essas alterações nos ambientes naturais, necessitam ser monitoradas. Várias são as formas de monitoramento, entre as quais pode-se citar as medições de parâmetros climáticos, a exemplo das temperaturas e umidades relativas do ar para análises de microclimas e o uso do sensoriamento remoto através de imagens de satélites que ajudam a mostrar o uso do solo em seus diferentes contextos (GÜLERSOY, 2013). 
Nesse sentido, Schiavo et al., (2015) relatam que a caracterização do uso do solo de propriedades rurais pode ser visualizada em imagens de sensoriamento remoto através de manchas de desmatamento.

O presente trabalho é importante, pois irá contribuir para o conhecimento cientifico a respeito do semiárido da Paraíba, ampliando as informações sobre suas características ambientais, fornecendo informações sobre as condições climáticas relacionadas ao uso do solo, sob perspectivas de desenvolvimento local.

O trabalho foi realizado em cinco pontos de uma mesma área da zona rural do município de São Bentinho-PB durante os meses de dezembro, janeiro e fevereiro, com usos do solo diferentes, os quais serão comparados entre si, apresentando a caracterização ambiental de cada ponto e a influência do uso dos solos com as condições climáticas por meio de medições de temperatura e umidade relativa do ar.

Sendo assim, o presente trabalho tem como objetivo analisar a influência do uso do solo em parâmetros climáticos em cinco pontos na zona rural no município de São Bentinho$\mathrm{PB}$, por meio de dados primários de temperatura e umidade relativa do ar.

\section{MATERIAIS E MÉTODOS}

Localização da área de estudo

O município de São Bentinho-PB está situado na região Nordeste do Brasil, no estado da Paraíba (Figura 1), está inserido na microrregião de Sousa com área de 888,807 $\mathrm{Km}^{2}$ e uma população de 32.110 habitantes (IBGE, 2010).

Figura 1 - Localização da área de estudo 


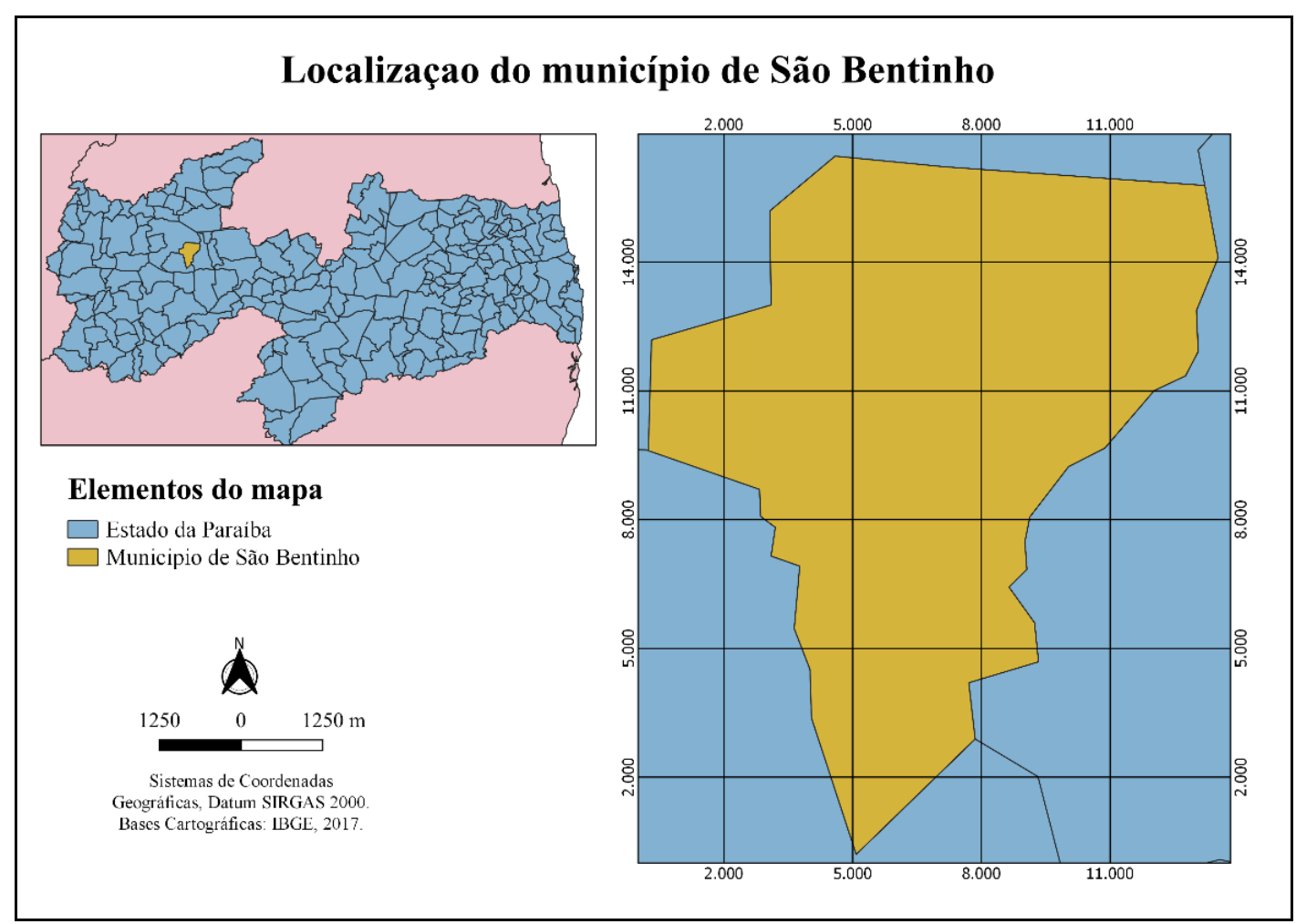

Fonte: Autores, 2019.

\section{Métodos}

A metodologia utilizada nesse trabalho consiste em fazer uma comparação com os valores de temperatura e umidade relativa do ar, das cinco amostras observadas com o uso do solo de cada uma delas. Para tanto, foi necessário fazer coleta de parâmetros climáticos e elaboração de mapa de uso do solo de cada uma das amostras.

\section{Coleta dos parâmetros climáticos}

O estudo foi realizado em uma área com cinco hectares, onde coletou-se amostras em cinco pontos. As amostras apresentaram cobertura de solo diferentes. A amostra 1 (ponto 1) foi coletada na área de Reserva Legal da propriedade, essa área é coberta de vegetação nativa preservada. A amostra 2 (ponto 2), em uma área sem vegetação nativa. A amostra 3 (ponto 3), numa área com residências. A amostra 4 (ponto 4) é próxima a barramento de águas e a última amostra (ponto 5) é localizada numa área de pastagens com predominância de vegetação nativa. Na figura 2, apresenta-se a localização das amostras dentro da área de estudo.

Figura 2 - Localização dos pontos de estudos 


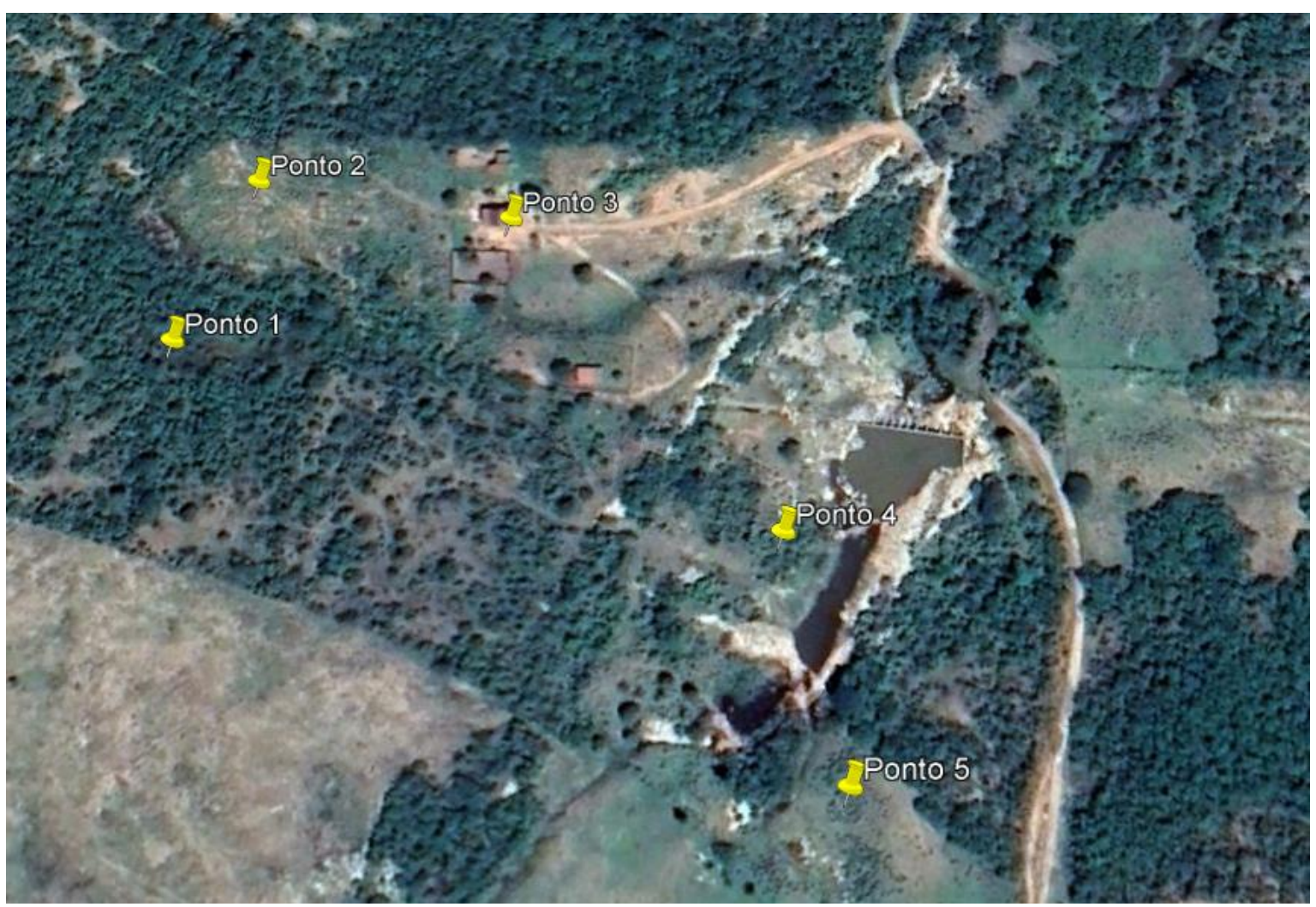

Fonte: Autores, 2019.

O critério usado para selecionar a área dos pontos de coleta foi envolver pontos com uso do solo diferentes dentro de uma mesma região.

Para cada ponto adotou-se um raio de alcance de $30 \mathrm{~m}^{2}$ e calculou-se a área de ocupação do solo dentro da delimitação do perímetro do raio.

Período de coleta de dados

Foram realizadas a coleta de temperatura do ar e umidade relativa do ar para caracterização do clima dentro do período estudado. Tais coletas foram realizadas em horários iguais por meio de equipamento apropriado, o termo-higrômetro (Figura 3) fixado a uma altura de 1,5 m do solo.

Figura 3 - Equipamento Termo-higrômetro 


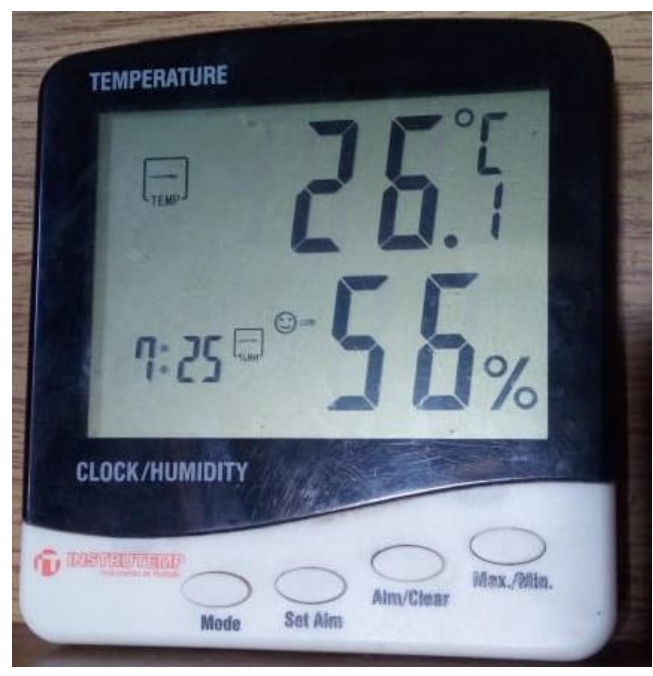

Fonte: Autores, 2019.

O período de coleta dos dados se estendeu por uma semana consecutiva ( 7 dias) ao longo de três meses da estação do verão (dezembro de 2018 e janeiro e fevereiro de 2019) iniciando ás 6:00h da manhã e finalizando às 18:00h, com intervalos de registros de três horas. O número de coletas diárias foi de cinco medições, com tempo de estabilização dos equipamentos de três minutos com diferença dos aparelhos de $0,7^{\circ} \mathrm{C}$.

Após a coleta das medições foi feito o cálculo da média das mesmas. Ao todo, foram realizadas 105 (cento e cinco) leituras. E por último a tabulação dos dados em planilhas do Excel, e a sua interpretação.

\section{Mapeamento do uso do solo}

Tais amostras foram determinadas coletando as coordenadas de cada uma delas com auxílio de GPS Garmin Maps 62 em campo e tratados posteriormente com o uso dos SIGs (Sistemas Informações Geográficas) com técnicas de sensoriamento remoto.

Utilizou-se imagem de satélite Landsat 5, sensor TM adquiridas no site do Instituto Nacional de Pesquisas Espaciais - INPE e processadas por classificação supervisionada no Sistema de Informações Geográficas (SIG) Qgis, versão 2.18.

As imagens utilizadas foram referentes as bandas 5, 4 e 3 de fevereiro de 2019 e órbita 216/65.

O uso do solo observado foi vegetação nativa, solo desnudo, construções e água. Em seguida, elaborou-se o mapa de uso do solo a partir da classificação da imagem.

\section{RESULTADOS}


Análise dos parâmetros climáticos

$\mathrm{Na}$ amostra 1 (Figura 4A) a menor temperatura foi de $25^{\circ} \mathrm{C}$ às 6:00h da manhã e a temperatura mais elevada foi registrada as $15: 00 \mathrm{hs}$ da tarde. Os resultados, quando comparados com os demais pontos obteve as menores temperaturas e menor taxa de variação da umidade relativa do ar. Isso ocorreu devido nesse ponto apresentar mais árvores, que apesar de estarem com poucas folhas devido as características naturais do bioma, se mostraram o suficiente para reduzir a temperatura do microclima.

Esses resultados são semelhantes aos encontrados por Silveira e Pereira (2011), os quais apresentam valores de temperatura mais amenos em áreas com cobertura vegetal; as plantas são responsáveis por oferecer sombra, que diminui a temperatura do ar.

Analisando-se os dados da amostra 2 (Figura 4B) pode-se perceber temperaturas mais elevadas e umidades relativas do ar mais baixas. A menor temperatura observada foi de $26^{\circ} \mathrm{C}$, às 6:00h da manhã como já era de se esperar. A maior temperatura foi registrada em $38,2{ }^{\circ} \mathrm{C}$ às 15:00h da tarde. Tais resultados, têm influência do solo desnudo encontrado nessa amostra.

Figura 4 - Média das temperaturas das amostras 1 e 2

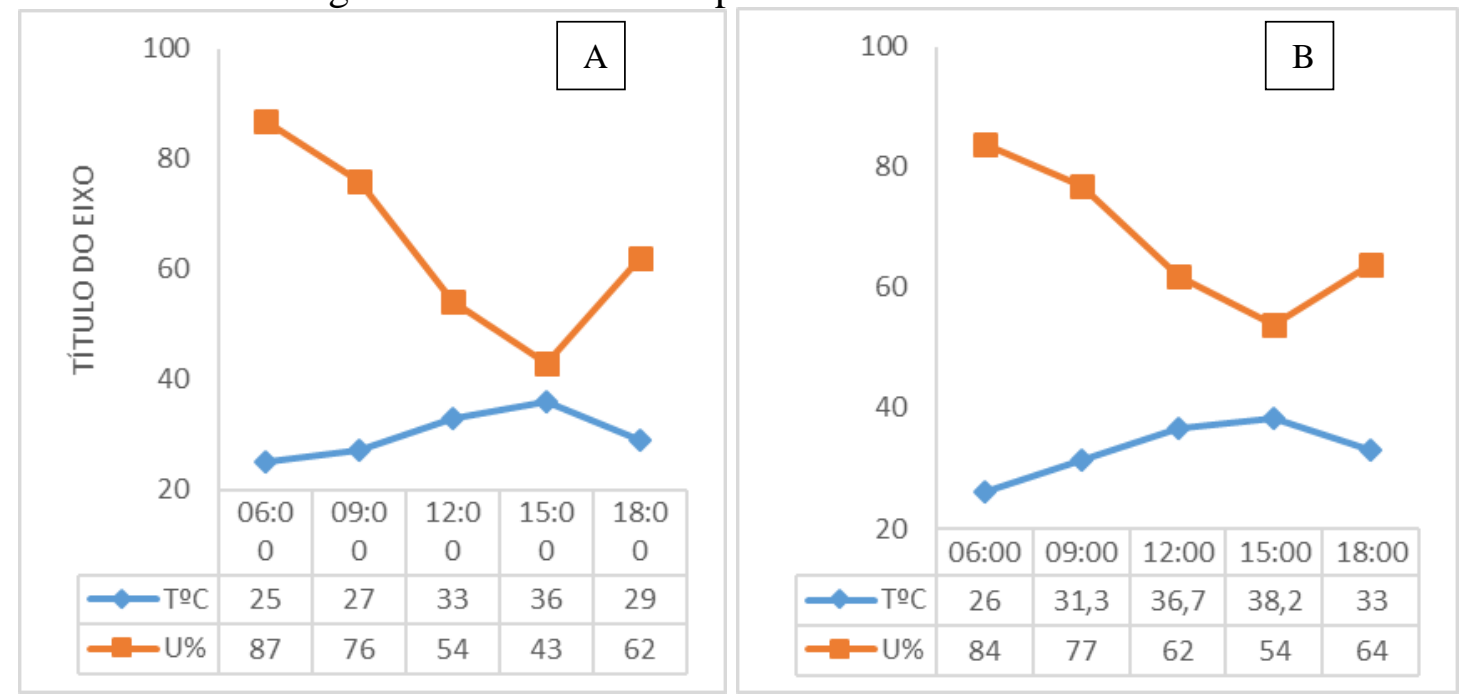

Fonte: Autores, 2019.

$\mathrm{Na}$ amostra 3 (Figura 5C), onde estão situadas as construções humanas, a temperatura mostrou-se por todo o período de análise um comportamento semelhante aos dois pontos. Temperaturas mais baixas na parte da manhã, $26^{\circ} \mathrm{C}$ e a mais elevada as $15: 00 \mathrm{hs}$ com 
$37,3{ }^{\circ} \mathrm{C}$. Esse valor de temperatura quando comparado com o uso do solo, mostrou-se influenciado pelo mesmo.

A penúltima amostra (Figura 5D) analisada, foi próxima ao barramento de água ao qual registrou às 6:00hs da manhã $26^{\circ} \mathrm{C}$ e $36,1^{\circ} \mathrm{C}$ na parte da tarde. Tais dados não sofreram redução, haja visto o corpo hídrico apresentar regime intermitente e nesse período o riacho se encontrar sem água.

Figura 5 - Média das temperaturas das amostras 3 e 4

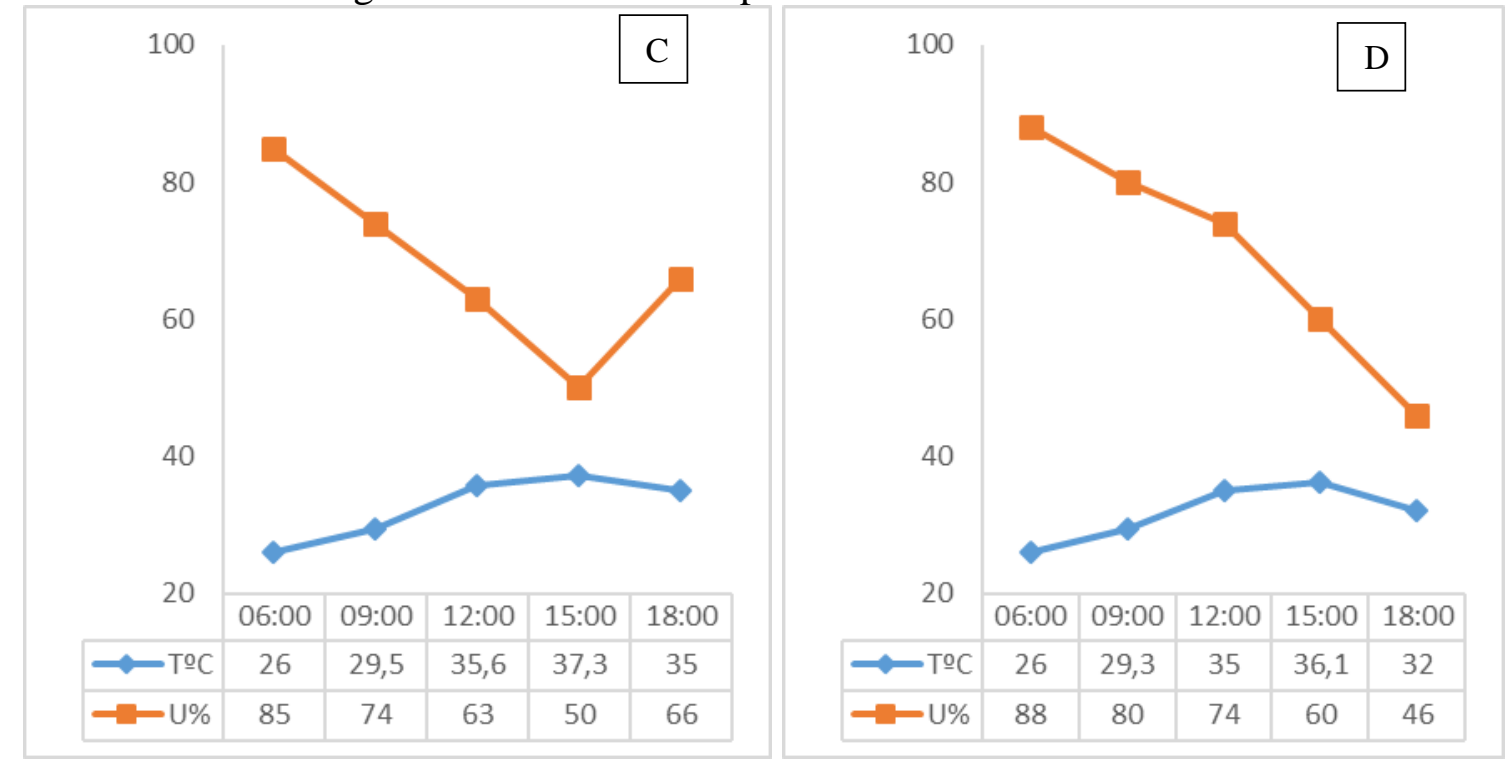

Fonte: Autores, 2019.

Na última amostra (Figura 6) a menor temperatura registrada às 6:00hs da manhã foi de $26^{\circ} \mathrm{C}$, com a maior de $36,7^{\circ} \mathrm{C}$ às $15: 00 \mathrm{hs}$.

Figura 6 - Média das temperaturas da amostra 5 
Revista de Geografia (Recife) V. 36, No. 2, 2019 - ISSN: 2238-6211

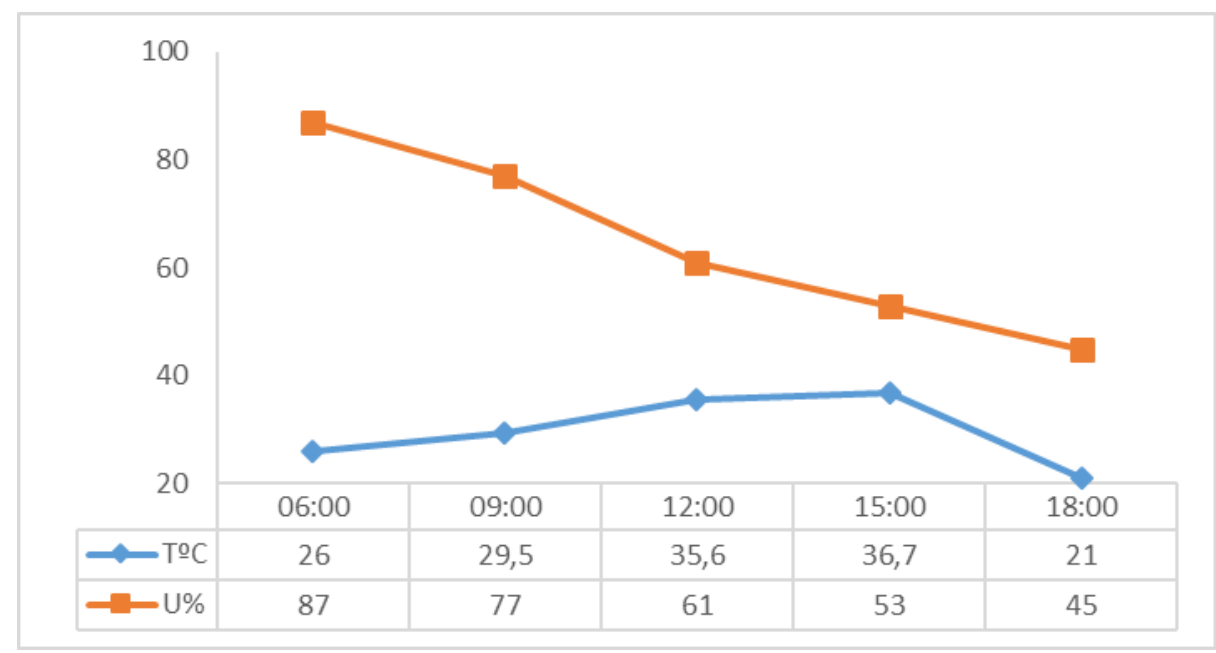

Fonte: Autores, 2019.

Analisando de forma geral, pode-se observar que em média, a temperatura do ar foi menor na amostra 1, devido a área ser caracterizada pela presença maior de vegetação, e a maior temperatura foi registrada na área da amostra 2, como já era de esperar.

Em relação aos horários, foi possível perceber que as maiores diferenças de temperatura ocorrem entre 13:00h e 14:00hs, o que pode ser explicado como uma das características da região de não dissipar o calor, mantendo temperaturas mais elevadas nas primeiras horas da tarde, devido ao maior tempo de absorção de calor. Nesta medição a diferença do valor de uma área para outra não ultrapassou de $2,2^{\circ} \mathrm{C}$.

Leal et al., (2008) cita que o microclima pode ser influenciado pela poluição do ar, pois o fenômeno do efeito estufa está aumentando a temperatura em nosso planeta, mas as diferenças de temperaturas desses pontos se refere apenas as diferenças do uso do solo, já que em nenhum dos pontos existem algum tipo de poluição.

\section{Mapeamento do uso do solo}

De acordo com a Figura 6 é possível visualizar a cobertura do solo para as 5 amostras estudados no período de dezembro de 2018 a fevereiro de 2019, as quais se encontram em áreas rurais próximas a residências, corpos de águas e áreas sem vegetação.

Figura 7 - Mapeamento do uso do solo das amostras analisadas 
Revista de Geografia (Recife) V. 36, No. 2, 2019 - ISSN: 2238-6211

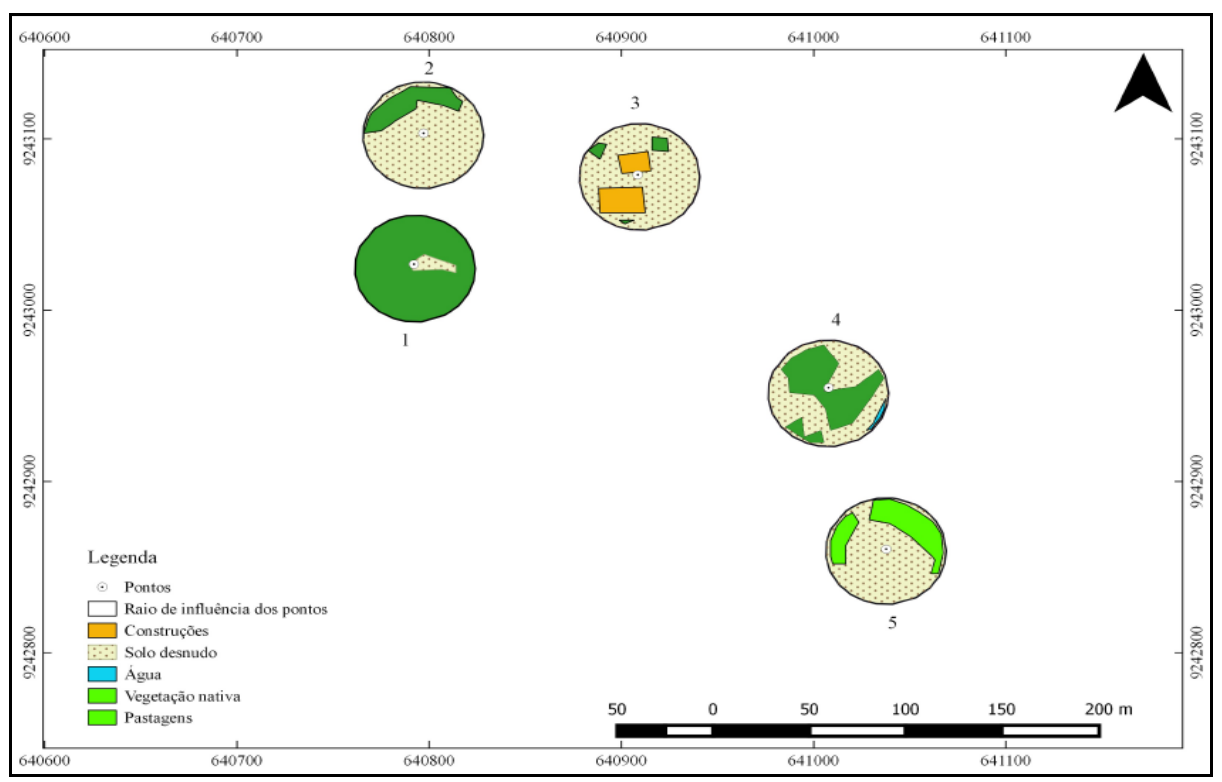

Fonte: Autores, 2019.

Observando a amostra 1, localizado na área de Reserva Legal, nota-se a predominância de $83 \%$ de vegetação nativa densa e $17 \%$ de solo descoberto. Segundo o Código Florestal de 2012, propriedades rurais do bioma caatinga devem manter preservados $20 \%$ da vegetação nativa, a fim de conservação das espécies e controle para desmatamento. Sendo assim tal ponto, se encontra inserido nesse bioma, e se mostra conservado.

Em relação a amostra 2, apenas $22 \%$ são de vegetação rasteira, composta por gramíneas e $78 \%$ do solo se encontra descoberto. Tal cenário, mostrou na visita de campo o desencadeamento de processos erosivos, decorrente da atual situação do solo.

A amostra 3, é composta por $12 \%$ de vegetação nativa, $77 \%$ de solo desnudo e $11 \%$ de área construída (residências e abrigos para animais).

Analisando a amostra 4, percebe-se que essa apresenta $62 \%$ de vegetação nativa, $30,9 \%$ de solo desnudo e 7,1\% de água. A proximidade ao corpo hídrico revela a necessidade de se manter essa área com vegetação nativa preservada, a fim de evitar o desencadeamento dos processos erosivos, e atender ao proposto no Novo Código Florestal.

Figura 8 - Amostra 4 


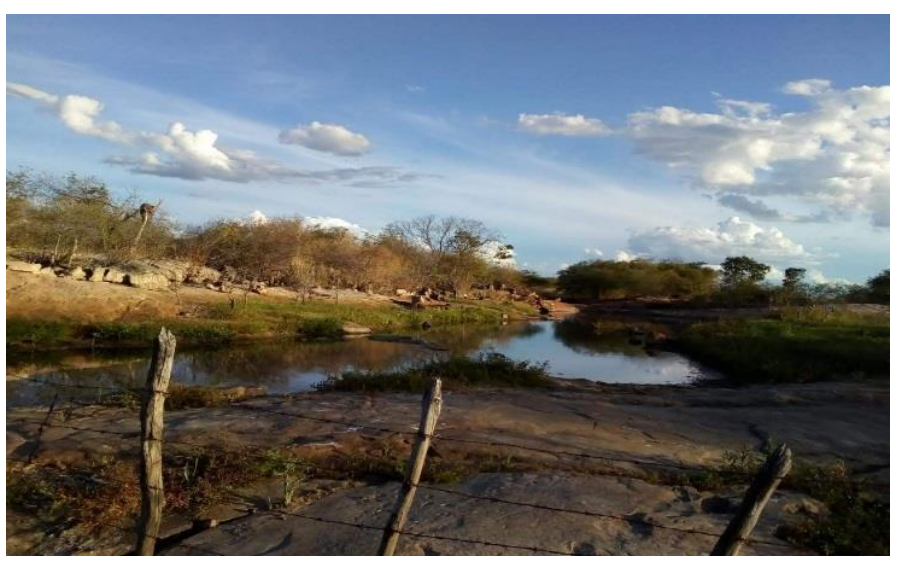

Fonte: Autores, 2019.

A amostra 5 é composta de três tipos de solos, $20 \%$ de vegetação nativa, $65 \%$ de solo desnudo e $15 \%$ de pastagens, conforme mostra a figura 8 .

\section{Figura 9 - Pastagens da amostra 5}

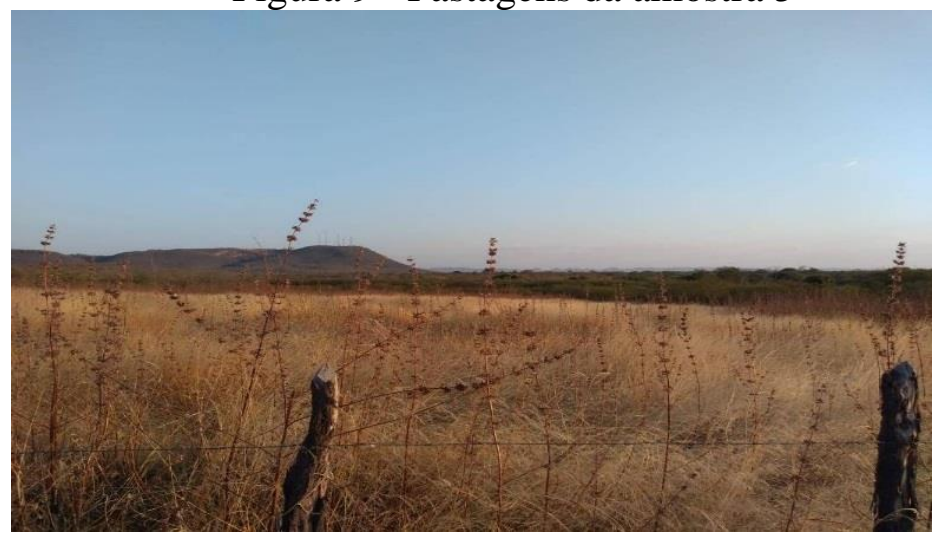

Fonte: Autores, 2019.

Na tabela abaixo, está apresentado o resumo de todas as informações coletadas para as 5 amostras de análises. Verificando cada amostra analisada foi possivel notar, que em um mesma amostra, em um raio de $30 \mathrm{~m}^{2}$ há mais de um tipo de uso do solo. Resultados semelhantes foram encontrados por Corazza, Neckel e Cambrussi (2018, p. 421) que observaram com imagens de satélites e técnicas de sensoriamento remoto diferentes tipos de uso do solo, em uma mesma área específica. Esses dados revelam a pressão sobre os recursos naturais.

Tabela 1 - Mapeamento do uso do solo das amostras analisadas 
Revista de Geografia (Recife) V. 36, No. 2, 2019 - ISSN: 2238-6211

\begin{tabular}{llllll}
\hline Cobertura do solo & Amostra & Amostra & Amostra & Amostra & Amostra \\
& $\mathbf{1}$ & $\mathbf{2}$ & $\mathbf{3}$ & $\mathbf{4}$ & $\mathbf{5}$ \\
\cline { 2 - 6 } & \multicolumn{2}{l}{ Áreas (\%) } & & & \\
\hline Vegetação nativa & 83 & 22 & 12 & 62 & 20 \\
\hline Solo desnudo & 17 & 78 & 77 & 30,9 & 65 \\
\hline Pastagens & 0 & 0 & 0 & 0 & 15 \\
\hline Água & 0 & 0 & 0 & 7,1 & 0 \\
\hline Construções & 0 & 0 & 11 & 0 & 0 \\
\hline
\end{tabular}

Fonte: Autores, 2019.

Com base na Figura 10, analisando de forma geral, pode-se observar que em todas as amostras foram encontrados vestígios de ação antrópica, haja vista nenhuma amostra estar $100 \%$ ocupado por vegetação nativa. Entretanto, o percentual de área ocupada por construções humanas é pequeno, as ações antrópicas revelam o desmatamento para pastagens e plantio. Tais resultados são similares aos do trabalho de Gülersoy em 2013, que utilizando imagens de satélites de diferentes datas para identificar as modificações que ocorreram no solo conseguiu observar os diferentes usos e a expansão urbana no município estudado. Sendo assim, é possível notar que cada vez mais cresce a mancha de uso do solo por despejo de mariscagem.

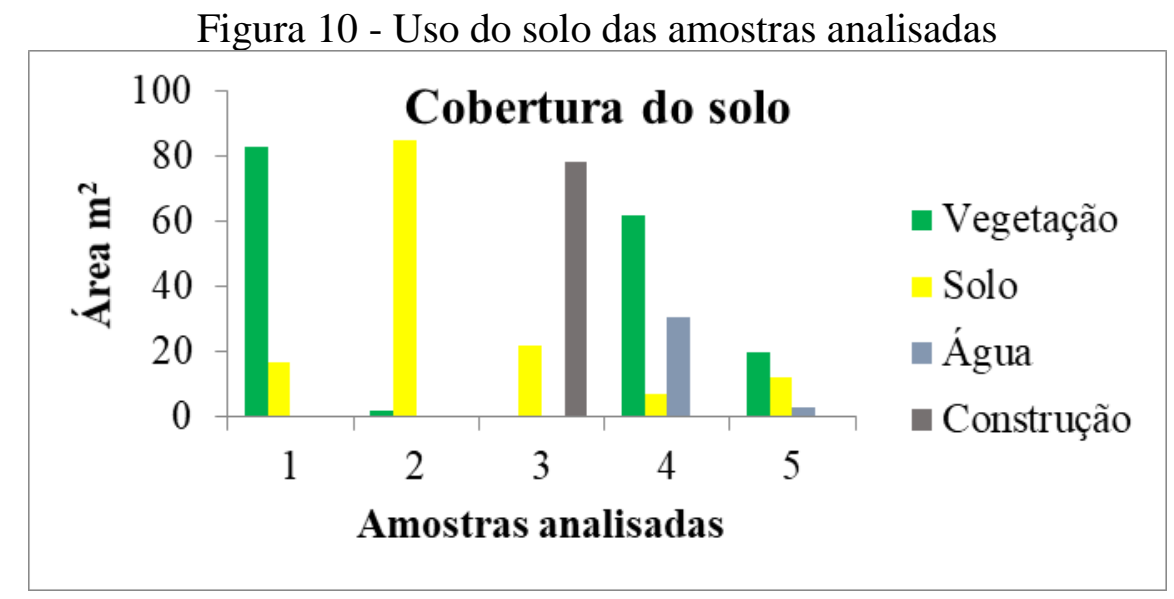

Fonte: Autores, 2019.

De forma geral, foi possível observar que o ponto 1 é o que apresenta menor foco de antropização seguido do ponto 4. Os últimos dois pontos apresentam áreas com maiores interferências devido a presença de atividades humanas. 


\section{CONCLUSÕES}

Os resultados mostram que todas as áreas sofreram antropização e tiveram suas qualidades naturais alteradas.

Percebe-se que os diferentes usos do solo influenciam diretamente na temperatura e umidade relativa do ar, mesmo o solo não sendo pavimentado e as árvores não oferecendo sombra.

As consequências da supressão da vegetação nativa em áreas rurais, são temperaturas mais elevadas e menos recursos naturais disponíveis;

Verifica-se também que a interferência humana pode contribuir para microclimas desagradáveis.

\section{REFERÊNCIAS}

BRASIL. Lei n. 12.651, de 25 de maio de 2012. Institui o Novo Código Florestal. Disponível em http://www.planalto.gov.br/CCivil_03/Leis/L4771.htm. Acesso em 28 junho de 2019.

CORAZZA, R.; NECKEL, A.; CAMBRUSSI, L. P. Avaliação das mudanças no uso do solo em áreas rurais no município de Passo Fundo/RS entre 1989 e 2011 com uso de imagens Landsat TM-5. Revista de Arquitetura IMED, Passo Fundo, vol. 7, n. 1, p. 68-83, 2018.

FOGLIATTI, M. C., FILIPPO, S.; GOUDARD, B. Avaliação de impactos ambientais: aplicação aos sistemas de transporte. Rio de Janeiro: Interciência, 2004.

GÜLERSOY, Ali Ekber. Farkli Uzaktan Algilama Teknikleri Kullanilarak Arazi Örtüsü/Kullaniminda meydana gelen değişimlerin incelenmesi: Manisa Merkez Ilçesi Örneği (1986-2010). Turkish Studies: International Periodical for the Languages, Literature and History of Turkish or Turkic, Turkey, v. 8, n. 8, p.1915-1934, ago. 2013.

IBGE. Instituto Brasileiro de Geografia e Estatística. Censo de 2010. Disponível em: <http://www.ibge.gov.br>. Acesso em 12 de jul. 2014. 
INSTITUTO NACIONAL DE PESQUISAS ESPACIAIS (INPE). Disponível em: <http://www.inpe.br/>. Acesso em 15 Mar 2014.

LEAL, G. C. S. de G.; FARIAS, M. S. S. de; ARAUJO, A. de F. O processo de industrialização e seus impactos no meio ambiente urbano. QUALIT@S Revista Eletrônica. ISSN 1677-4280 V.7, n.1, 2008.

LIMA, B. R. de O. Poluentes da atmosfera urbana e a influência dos sistemas meteorológicos na quantificação destes compostos no município de Ourinhos/SP. REVISTA GEONORTE, Edição Especial, V.2, N.4, p.1035 - 1047, 2012.

PIRES, D. O. Inventário de Emissões Atmosféricas de Fontes Estacionárias e sua Contribuição para a Poluição do Ar na Região Metropolitana do Rio de Janeiro. 2005. 194 f. VI, 188 p. Tese - Universidade Federal do Rio de Janeiro, COPPE. 2005.

SCHIAVO, B. N. de V.; TERRA, L. G.; DUARTE, M. M.; GATIBONI, T. N. Uso de imagens orbitais multitemporais para caracterização de uso e ocupação da terra no município de São Borja. Revista Eletrônica em Gestão, Educação e Tecnologia Ambiental Santa Maria, v. 19, n. 2, mai-ago. 2015, p. 1526-1534.

SILVEIRA, M. H. D.; PEREIRA, L. R. Influência da arborização urbana no microclima de duas áreas na região central de Rondonópolis - MT. ENCICLOPÉDIA BIOSFERA, Centro Científico Conhecer - Goiânia, vol.7, N.13, 2011. 